\title{
Predictors of Complementary and Alternative Medicine Use in Cancer Care: Results of a Nationwide Multicenter Survey in Korea
}

\author{
Ji-Yeon Shin, ${ }^{1}$ So Young Kim, ${ }^{1}$ Boyoung Park, ${ }^{1}$ Jae-Hyun Park, ${ }^{2}$ \\ Jin Young Choi, ${ }^{1}$ Hong Gwan Seo, ${ }^{1}$ and Jong-Hyock Park ${ }^{1}$ \\ ${ }^{1}$ National Cancer Control Institute, National Cancer Center, Goyang, 323 Ilsan-ro, Ilsandong-Gu, Goyang-si, \\ Gyeonggi-do 410-769, Republic of Korea \\ ${ }^{2}$ Department of Social and Preventive Medicine, Sungkyunkwan University School of Medicine, 2066 Seobu-ro, Jangan-gu, \\ Suwon-si 440-746, Republic of Korea
}

Correspondence should be addressed to Jong-Hyock Park, whitemiso@ncc.re.kr

Received 17 September 2012; Accepted 25 November 2012

Academic Editor: David Mischoulon

Copyright (C) 2012 Ji-Yeon Shin et al. This is an open access article distributed under the Creative Commons Attribution License, which permits unrestricted use, distribution, and reproduction in any medium, provided the original work is properly cited.

\begin{abstract}
Background. Although studies have shown that the use of complementary and alternative medicine (CAM) is common in cancer patients, few surveys have assessed CAM use and associated factors in various cancers in Korea. Objectives. We explored factors predicting CAM use among a nationally representative sample of cancer patients. Methods. In total, 2,661 cancer patients were administered questionnaires about their CAM use and factors that might predict CAM use including sociodemographics, clinical and quality-of-life factors, time since diagnosis, trust in physicians, trust in hospitals, satisfaction, and informational needs. Data were analyzed using Pearson's $\chi^{2}$ tests and multivariate logistic regression analysis. Results. Overall, 25.5\% reported that they had used or were using CAM. Higher income, presence of metastasis, longer time since diagnosis, less trust in hospitals, lower overall satisfaction, and higher degree of informational need were significantly associated with CAM use. Conclusions. The use of CAM in patients with cancer can be interpreted as an attempt to explore all possible options, expression of an active coping style, or expression of unmet needs in the cancer care continuum. Physicians need to openly discuss the use of CAM with their patients and identify whether they have other unmet supportive needs.
\end{abstract}

\section{Introduction}

The National Center for Complementary and Alternative Medicine (NCCAM) defines complementary and alternative medicine (CAM) as "diverse medical and healthcare systems, practices and products that are not generally considered a part of conventional medicine" [1]. Despite advances in the medical treatment of cancer that have resulted in improved cure rates, the incidence of cancer is increasing, and it remains a leading cause of death [2]. At the same time, there is an increasing tendency for patients with cancer to use CAM by [3]. In patients with breast cancer, the rate of CAM use increased from 67\% to 82\% between 1998 and 2005 [4]. Furthermore, CAM use was reported in up to $90 \%$ of patients with cancer in the United States $[5,6]$ and $44.6 \%$ of those in Japan [7].

From a clinical perspective, it is important to identify factors that encourage large numbers of patients with cancer to use CAM, solely or concomitantly with conventional medical treatments, because cancer patients frequently face situations that are subjectively less controllable and more frightening than other chronic or life-threatening diseases [8]. Previous studies have suggested that the rate of CAM use depends on sociodemographic characteristics of patients, cancer-related clinical characteristics, regional and cultural factors, and patients' patterns of coping with the disease [9]. Younger age $[7,10]$, female gender $[10,11]$, a higher level of education $[7,10,12]$, and higher income and social class $[10,11]$ seem to be associated with more frequent use of CAM. Additionally, it has been reported that a higher rate of CAM use is associated with a longer duration since diagnosis [13], progression of the cancer $[10,12,14]$, and a lower degree of trust in physicians [10,15].

Meanwhile, few studies have been conducted to examine the relationship between the unmet informational needs and the use of CAM in patients with cancer, although the topic 
of unmet needs has been a recurrent on in CAM-related studies [10]. In patients with cancer, informational support provides a sense of control over the illness [16] and enhances patients' quality of life when information meets their needs [17]. Accordingly, unmet needs for information may cause distress in patients [18], thus possibly affecting their pattern of use of medical services. It is thus important that the degree of patient need for information is examined as a possible predictor of CAM use.

In Korea to date, almost no nationwide studies have been reported examining the use of CAM and relevant factors. Most previous studies have been conducted at a few hospitals in a specific region. The rate of CAM use varies depending on the study; it was reported to be $63.7 \%$ by Kim [19], 55.5\% by Lee et al. [20], and $56.9 \%$ by Park and Lee [21]. It is worthwhile to examine the current status of CAM use in patients with cancer and to develop the best policy for them. To do this, it is important to collect baseline data that can be generalized for various types of cancer in varying stages. This should also be accompanied by access to comprehensive cancer care to achieve a better understanding of the factors affecting CAM use and relevant reasons.

Given this background, we conducted this study with the following objectives: (1) to evaluate the status of CAM use based on nationwide data in patients with various types of cancer; (2) to examine factors affecting CAM use, including socioeconomic, clinical, and individual factors, in patients with cancer; and (3) to identify any association between informational needs and CAM use in patients with cancer.

\section{Materials and Methods}

2.1. Study Patients and Procedure. For the current study, we collected data from patients with cancer who were treated at the National Cancer Center or nine regional cancer centers in Korea during the period from July to August 2008. Quota sampling was used: $80 \%$ of the patients had been diagnosed with one of six major types of cancer (stomach, lung, liver, colon and rectum, breast, and cervix), and the remaining $20 \%$ had other types of cancer. The patients were interviewed by trained interviewers at their treatment centers. Inclusion criteria were (1) age $>18$ years old, (2) an established diagnosis of cancer, (3) a period $>4$ months since the diagnosis, (4) current treatments or follow-ups, and (5) written informed consent for study participation. Detailed procedures have been described elsewhere [22]. In total, 2,661 patients with cancer completed an interview. Then, through a retrospective analysis of the patients' medical records, we obtained clinical data such as types, histology, and SEER stage of the cancers. The current study was approved by the institutional review board (IRB) of the National Cancer Center in Korea.

2.2. Measurement and Analysis of the Patient Data. A questionnaire survey was designed to collect data about CAM use and potential predictors (sociodemographic and clinical factors, quality of life, the degree of trust in physicians and hospitals, degree of satisfaction with conventional medicine, and degree of need for information).

We defined CAM based on the widely established NCCAM taxonomy [1] and included alternative medical systems, mind and body interventions, natural products, manipulative and body-based methods, and energy therapies. The specific CAM modalities asked about in this study were traditional Chinese medicine, ayurveda, herbalism, acupuncture, meditation, yoga, biofeedback, hypnosis, relaxation, imagery, prayer, chiropractic, massage, special diets, dietary supplements, qi gong, and healing touch. According to NCCAM, we did not include pure psychotherapeutics or support groups, and we excluded general exercises to avoid overestimation.

In the questionnaire survey, patients were asked about their experience using CAM with the question, "Have you ever used complementary and alternative medicines (CAM) since you were diagnosed with cancer?" Patient responses were collected as a dichotomized variable. Sociodemographic factors included age, gender, education, income, marital status, and health insurance status. Clinical factors included the type of cancer, SEER stage, treatment, time since the diagnosis, and current disease status. Additionally, quality of life was measured using the EQ5D, which measures five dimensions of patient quality of life (mobility, self-care, usual activities, pain/discomfort, and anxiety/depression) using a 3 -point scoring system ( $1=$ no problem, $2=$ some problems, and 3 = severe problems). The EQ5D has been validated for Korean subjects [23]. We classified responses to the EQ5D into two categories: patients who had at least one problem and those who had no problem.

The degree of trust in physicians and hospital was measured using a 5 -point Likert scale ( $1=$ strongly disagree and 5 = strongly agree), and responses were classified into three categories: very satisfied, somewhat satisfied, and not satisfied.

The overall degree of satisfaction with conventional cancer care was measured with a 5 -point Likert scale $(1=$ very dissatisfied and $5=$ very satisfied), and responses were then dichotomized (satisfied or very satisfied versus others) for further analyses.

The degree of patient need for information was measured using a subscale of the Comprehensive Needs Assessment Tool (CNAT) in cancer, which has been validated for Korean subjects [24]. Patients were instructed to evaluate items on a 4-point scale (never needed, slightly needed, moderately needed, and highly needed) based on the past month's experience. Responses were then classified for further analysis into binary variables: "never needed" versus "needed" (slightly needed, moderately needed, or highly needed).

2.3. Statistical Analysis. We used the chi-squared test to analyze differences in the rates of CAM use between the categories of selected demographic and clinical variables (age, gender, education, marital status, monthly income, national health insurance, cancer type, metastasis, SEER stage, and time since diagnosis). Additionally, we performed a univariate analysis of factors predicting CAM use. Then, 
TABLE 1: Characteristics of cancer patients and complementary and alternative medicine use.

\begin{tabular}{|c|c|c|c|c|}
\hline Variables & Number of patients & Number of users & $\%$ & $P\left(X^{2}\right.$ test $)$ \\
\hline Total & 2661 & 678 & 25.5 & \\
\hline \multicolumn{5}{|l|}{ Age (year) } \\
\hline $18-39$ & 185 & 50 & 27.0 & \\
\hline $40-59$ & 1171 & 355 & 30.3 & \\
\hline $60-69$ & 791 & 176 & 22.3 & \\
\hline $70+$ & 514 & 97 & 18.9 & $<0.001$ \\
\hline \multicolumn{5}{|l|}{ Gender } \\
\hline Male & 1412 & 316 & 22.4 & \\
\hline Female & 1249 & 362 & 29.0 & $<0.001$ \\
\hline \multicolumn{5}{|l|}{ Education } \\
\hline$\leq$ Middle school & 1378 & 295 & 21.4 & \\
\hline High school & 836 & 249 & 29.8 & \\
\hline$\geq$ College & 436 & 130 & 29.8 & $<0.001$ \\
\hline \multicolumn{5}{|l|}{ Marital status } \\
\hline Married & 2212 & 577 & 26.1 & \\
\hline Not married (single, divorced, and widowed) & 446 & 100 & 22.4 & 0.105 \\
\hline \multicolumn{5}{|l|}{ Monthly household income } \\
\hline$<1000$ USD & 803 & 155 & 19.3 & \\
\hline 1000-3000 USD & 1138 & 300 & 26.4 & \\
\hline$\geq 3000$ USD & 705 & 218 & 30.9 & $<0.001$ \\
\hline \multicolumn{5}{|l|}{ National Health Insurance } \\
\hline National Health Insurance & 2297 & 594 & 25.9 & \\
\hline Medicaid/none/others & 364 & 84 & 23.0 & 0.137 \\
\hline \multicolumn{5}{|l|}{ Cancer type } \\
\hline Stomach & 464 & 103 & 22.2 & \\
\hline Lung & 322 & 77 & 23.9 & \\
\hline Liver & 254 & 70 & 27.6 & \\
\hline Colon/rectum & 340 & 64 & 18.8 & \\
\hline Breast & 379 & 146 & 38.5 & \\
\hline Cervix & 113 & 31 & 27.4 & \\
\hline Others & 789 & 187 & 23.7 & $<0.001$ \\
\hline \multicolumn{5}{|l|}{ Metastasis } \\
\hline No & 1901 & 438 & 23.0 & \\
\hline Yes & 637 & 202 & 31.7 & $<0.001$ \\
\hline \multicolumn{5}{|l|}{ SEER stage } \\
\hline In situ and local & 1038 & 251 & 24.2 & \\
\hline Regional & 918 & 235 & 25.6 & \\
\hline Distant & 468 & 125 & 26.7 & \\
\hline Unknown & 237 & 67 & 28.3 & 0.517 \\
\hline \multicolumn{5}{|l|}{ Time since diagnosis } \\
\hline$\leq 12$ months & 985 & 204 & 20.7 & \\
\hline 12-36 months & 909 & 234 & 25.7 & \\
\hline 36-60 months & 385 & 120 & 31.2 & \\
\hline$>60$ months & 382 & 120 & 31.4 & $<0.001$ \\
\hline \multicolumn{5}{|l|}{ Trust in doctor } \\
\hline Very & 2335 & 575 & 24.6 & \\
\hline Somewhat & 292 & 88 & 31.1 & \\
\hline Not at all & 34 & 15 & 44.1 & 0.005 \\
\hline \multicolumn{5}{|l|}{ Trust in hospital } \\
\hline Very & 2125 & 514 & 24.2 & \\
\hline Somewhat & 480 & 141 & 29.4 & \\
\hline Not at all & 56 & 23 & 41.1 & 0.002 \\
\hline
\end{tabular}


Table 1: Continued.

\begin{tabular}{|c|c|c|c|c|}
\hline Variables & Number of patients & Number of users & $\%$ & $P\left(X^{2}\right.$ test $)$ \\
\hline \multicolumn{5}{|c|}{ Satisfaction with medical service } \\
\hline Very & 1837 & 439 & 23.9 & \\
\hline Somewhat & 673 & 185 & 27.5 & \\
\hline Not at all & 151 & 54 & 35.8 & 0.002 \\
\hline \multicolumn{5}{|l|}{ EQ5D } \\
\hline No problem & 987 & 223 & 22.6 & \\
\hline One or more problem & 1674 & 455 & 27.2 & 0.009 \\
\hline
\end{tabular}

we entered variables found to be significantly associated with CAM use in the univariate analysis into a multiple logistic regression model. The criterion for variable entry was $P=$ 0.05. Age, gender, education, monthly income, cancer type, metastasis, and time since diagnosis were included in a basic predictive model. EQ5D, trust in physicians and hospitals, overall degree of satisfaction with the conventional cancer care, and degree of patient need for information were also analyzed individually for their associations with the use of CAM following adjustment of variables in the basic model. Data from patients with missing values were excluded from the multiple logistic regression model. All statistical analyses were performed using the SAS 9.2 software (SAS Institute, Cary, NC, USA). Statistical significance was set at $P<0.05$.

\section{Results}

Table 1 summarizes baseline characteristics of all study patients, including those who used CAM. Of the 2,661 total respondents, $25.5 \%$ responded that they had used CAM. The rate of CAM use was relatively higher in women, the age group between 40 and 59 years, and the group with monthly household income over USD 3000. With regard to type of cancer, CAM use was relatively higher in patients with breast cancer. It was also relatively higher in patients who had metastasis, those with a longer duration since diagnosis, those who had a lower degree of trust in physicians or hospitals, and those who had a lower overall degree of satisfaction with the cancer treatment offered by hospitals. Furthermore, from the perspective of quality of life, the rate of CAM use was relatively higher in patients who responded that they had a problem in more than one area covered by the five EQ5D questions.

A univariate analysis was performed for the variables presented in Table 1. This was followed by a multivariate analysis of variables showing a significant association with CAM use. The basic model included variables of gender, age, education, monthly income, cancer type, metastasis, and timing of diagnosis. Variables showing a significant association with CAM use in the univariate analysis, including gender, age, and education, no longer showed significant associations or showed a lower degree of association following adjustment for other variables. However, monthly income, cancer type, metastasis, and the duration since diagnosis maintained significant associations with CAM use even following the adjustment for other variables. Next, we performed a multivariate logistic regression analysis including trust in physicians and hospitals, overall degree of satisfaction with conventional medical service, and the EQ5D scores individually in a basic model. Even after controlling for socioeconomic and clinical factors, lower degree of trust in physicians or hospitals (aOR 2.38, 95\% CI 1.13-5.00; aOR 2.04, 95\% CI 1.15-3.63, resp.), and lower overall degree of satisfaction with the hospital (aOR 1.61, 95\% CI 1.11-2.34) were significantly associated with the use of CAM. With regard to EQ5D, the patients who responded that they had a problem in one or more of the areas addressed in the EQ5D were 1.23 times (95\% CI 1.01-1.50) more likely to use CAM compared with those who responded that they had no problems (Table 2 ).

The analysis of the association between the use of CAM and the degree of patient need for information indicated that CAM use was predicted by higher degree of informational need. Patients who responded that they were in need of information about the status and further course of the disease, the test and treatment methods, correct diet, and availability of financial support for patients with cancer were more likely to use CAM. Of the nine questions related to this issue, only the question about hospice showed no significant association with the use of CAM (Table 3).

\section{Discussion}

We conducted the current multicenter study to extensively analyze factors affecting the rate of CAM use in patients with various cancers in varying stages. Our results showed that sociodemographic factors affected the use of CAM, consistent with previous studies [7, 10-12]. A multivariate analysis showed that such sociodemographic factors as younger age (but not the youngest) and high monthly income had a significant association with the rate of CAM use. A higher level of education was also a marginal predictor of CAM use. Moreover, clinical factors, including metastasis, primary cancer site, and time since diagnosis, were also significantly associated with the use of CAM even after adjustment for sociodemographic factors. The result that metastatic cancer patients were more likely to use CAM suggests that patients at an advanced stage tend to use every method available to supplement conventional medicine. The association between progression of cancer and CAM use has been reported previously $[10,12,14]$. According to Paltiel et al., a poor progress may lead to increased level of concern 
TABLE 2: Predictors of complementary and alternative medicine use.

\begin{tabular}{|c|c|c|c|c|}
\hline \multirow{2}{*}{ Variables } & \multicolumn{2}{|c|}{ Univariate analysis } & \multicolumn{2}{|c|}{ Multivariate analysis } \\
\hline & OR & $95 \%$ CI & OR & $95 \% \mathrm{CI}$ \\
\hline \multicolumn{5}{|l|}{ Basic model $(n=2515)$} \\
\hline \multicolumn{5}{|l|}{ Age (year) } \\
\hline $18-39$ & 1.00 & Reference & 1.00 & Reference \\
\hline $40-59$ & 1.18 & $0.83-1.66$ & 1.36 & $0.93-1.99$ \\
\hline $60-69$ & 0.77 & $0.54-1.11$ & 1.18 & $0.78-1.80$ \\
\hline $70+$ & 0.63 & $0.42-0.93$ & 1.21 & $0.71-1.77$ \\
\hline \multicolumn{5}{|l|}{ Gender } \\
\hline Male & 1.00 & Reference & 1.00 & Reference \\
\hline Female & 1.42 & $1.19-1.69$ & 1.17 & $0.93-1.48$ \\
\hline \multicolumn{5}{|l|}{ Education } \\
\hline$\leq$ Middle school & 1.00 & Reference & 1.00 & Reference \\
\hline High school & 1.56 & $1.28-1.90$ & 1.31 & $1.05-1.65$ \\
\hline$\geq$ College & 1.56 & $1.22-1.99$ & 1.26 & $0.94-1.70$ \\
\hline \multicolumn{5}{|c|}{ Monthly household income } \\
\hline$<1000$ USD & 1.00 & Reference & 1.00 & Reference \\
\hline 1000-3000 USD & 1.50 & $1.20-1.86$ & 1.34 & $1.05-1.72$ \\
\hline$\geq 3000$ USD & 1.87 & $1.48-2.37$ & 1.57 & $1.18-2.10$ \\
\hline \multicolumn{5}{|l|}{ Cancer type } \\
\hline Stomach & 1.00 & Reference & 1.00 & Reference \\
\hline Lung & 1.10 & $0.79-1.54$ & 1.20 & $0.84-1.72$ \\
\hline Liver & 1.33 & $0.94-1.90$ & 1.25 & $0.86-1.83$ \\
\hline Colon/rectum & 0.81 & $0.57-1.15$ & 0.77 & $0.53-1.11$ \\
\hline Breast & 2.20 & $1.63-2.97$ & 1.79 & $1.24-2.56$ \\
\hline Cervix & 1.33 & $0.83-2.12$ & 1.05 & $0.63-1.77$ \\
\hline Others & 1.09 & $0.83-1.43$ & 1.05 & $0.78-1.41$ \\
\hline \multicolumn{5}{|l|}{ Metastasis } \\
\hline No & 1.00 & Reference & 1.00 & Reference \\
\hline Yes & 1.55 & $1.27-1.89$ & 1.55 & $1.26-1.91$ \\
\hline \multicolumn{5}{|l|}{ Time since diagnosis } \\
\hline$\leq 12$ months & 1.00 & Reference & 1.00 & Reference \\
\hline $12-36$ months & 1.33 & $1.07-1.64$ & 1.32 & $1.05-1.65$ \\
\hline 36-60 months & 1.73 & $1.33-2.26$ & 1.79 & $1.35-2.38$ \\
\hline$>60$ months & 1.75 & $1.35-2.29$ & 1.76 & $1.33-2.34$ \\
\hline \multicolumn{5}{|c|}{$\begin{array}{l}\text { Extended model } \\
\end{array}$} \\
\hline \multicolumn{5}{|l|}{ Trust in doctor } \\
\hline Very & 1.00 & Reference & 1.00 & Reference \\
\hline Somewhat & 1.32 & $1.01-1.73$ & 1.26 & $0.94-1.67$ \\
\hline Not at all & 2.42 & $1.22-4.79$ & 2.38 & $1.13-5.00$ \\
\hline \multicolumn{5}{|c|}{ Extended model $2(n=2515)$} \\
\hline \multicolumn{5}{|l|}{ Trust in hospital } \\
\hline Very & 1.00 & Reference & 1.00 & Reference \\
\hline Somewhat & 1.30 & $1.05-1.63$ & 1.18 & $0.93-1.49$ \\
\hline Not at all & 2.19 & $1.27-3.76$ & 2.04 & $1.15-3.63$ \\
\hline \multicolumn{5}{|c|}{ Extended model $3(n=2515)$} \\
\hline \multicolumn{5}{|c|}{ Satisfaction with medical service } \\
\hline Very & 1.00 & Reference & 1.00 & Reference \\
\hline Somewhat & 1.21 & $1.99-1.78$ & 1.14 & $0.92-1.41$ \\
\hline Not at all & 1.77 & $1.25-2.52$ & 1.61 & $1.11-2.34$ \\
\hline
\end{tabular}


TABle 2: Continued.

\begin{tabular}{|c|c|c|c|c|}
\hline \multirow{2}{*}{ Variables } & \multicolumn{2}{|c|}{ Univariate analysis } & \multicolumn{2}{|c|}{ Multivariate analysis } \\
\hline & OR & $95 \% \mathrm{CI}$ & OR & $95 \% \mathrm{CI}$ \\
\hline \multicolumn{5}{|l|}{ Extended model $4(n=2515)$} \\
\hline \multicolumn{5}{|l|}{ EQ5D } \\
\hline No problems & 1.00 & Reference & 1.00 & Reference \\
\hline One or more problems & 1.28 & $1.06-1.54$ & 1.23 & $1.01-1.50$ \\
\hline
\end{tabular}

*Extended models are for individual current attitudes or status, controlling for the variables in the basic model.

TABLE 3: Informational needs and complementary and alternative medicine use.

\begin{tabular}{|c|c|c|c|c|}
\hline \multirow{2}{*}{ Variables } & \multirow{2}{*}{$\begin{array}{l}\text { Number of users/Number of } \\
\text { patients }\end{array}$} & \multirow{2}{*}{$\%$} & \multicolumn{2}{|c|}{ Multivariate analysis* } \\
\hline & & & OR & $95 \% \mathrm{CI}$ \\
\hline \multicolumn{5}{|c|}{ Needed information about the current status of my illness and its future course } \\
\hline No & $143 / 751$ & 19.0 & 1.00 & Reference \\
\hline Yes & $535 / 1910$ & 28.0 & 1.61 & $1.29-2.02$ \\
\hline \multicolumn{5}{|c|}{ Needed information about tests and treatments } \\
\hline No & $152 / 814$ & 18.7 & 1.00 & Reference \\
\hline Yes & $526 / 1847$ & 28.5 & 1.68 & $1.35-2.09$ \\
\hline \multicolumn{5}{|c|}{ Needed information about symptoms requiring a hospital visit } \\
\hline No & $187 / 897$ & 20.9 & 1.00 & Reference \\
\hline Yes & $491 / 1764$ & 27.8 & 1.44 & $1.17-1.78$ \\
\hline \multicolumn{5}{|c|}{ Needed an easy and accurate explanation of the benefits, side effects, and application of current medication } \\
\hline No & $240 / 1103$ & 21.8 & 1.00 & Reference \\
\hline Yes & $437 / 1556$ & 28.1 & 1.33 & $1.10-1.62$ \\
\hline \multicolumn{5}{|c|}{ Needed information about what I could do at home for my health (e.g., exercise) } \\
\hline No & $191 / 936$ & 20.4 & 1.00 & Reference \\
\hline Yes & $487 / 1725$ & 28.2 & 1.49 & $1.21-1.83$ \\
\hline \multicolumn{5}{|c|}{ Needed information about correct diet (foods to eat, foods to avoid) } \\
\hline No & $173 / 894$ & 19.4 & 1.00 & Reference \\
\hline Yes & $504 / 1765$ & 28.6 & 1.63 & $1.32-2.02$ \\
\hline \multicolumn{5}{|c|}{ Needed information about cancer-treating hospitals or clinics and physicians } \\
\hline No & $243 / 1196$ & 20.3 & 1.00 & Reference \\
\hline Yes & $435 / 1465$ & 29.7 & 1.51 & $1.25-1.84$ \\
\hline \multicolumn{5}{|c|}{ Needed information about governmental financial support for medical expenses } \\
\hline No & $137 / 708$ & 19.4 & 1.00 & Reference \\
\hline Yes & $541 / 1951$ & 27.7 & 1.56 & $1.25-1.96$ \\
\hline \multicolumn{5}{|c|}{ Needed information about hospice services } \\
\hline No & $476 / 1925$ & 24.7 & 1.00 & Reference \\
\hline Yes & $192 / 715$ & 26.9 & 1.04 & $0.84-1.29$ \\
\hline
\end{tabular}

* Multivariate analysis was performed on individual informational need, controlling for the variables in the basic model (gender, age, monthly income, cancer type, metastasis, and time since diagnosis).

or distress and a desire to explore all possible options. Our results also showed that the rate of CAM use was relatively higher in patients with breast cancer, also in agreement with previous reports [25-27]. It has been reported worldwide that the rate of CAM use is highest in patients with breast cancer [26]. This finding may be confounded by the fact that more women use CAM than men [28] and should be interpreted cautiously. Gender was included as a variable in a multivariate analysis, which might dilute the association between gender and use of CAM in patients with breast cancer. On the other hand, it is also probable that the genderrelated difference in the rate of CAM use might be diluted following the adjustment for breast cancer. Our results might be interpreted in the latter manner.

After controlling for basic factors in the multivariate analysis, the degree of trust in physicians and hospitals was 
strongly associated with the use of CAM. A lower degree of trust in physicians was associated with more frequent use of CAM, and the same was also true of the association between the degree of trust in hospitals and CAM use. This is supported by several studies. According to Cassileth et al., doctor-patient relationships were worse in patients who underwent both conventional therapy and CAM compared with patients who underwent conventional therapy alone [15]. Additionally, Paltiel et al. reported that the rate of CAM use was relatively lower in patients who had a higher degree of trust in physicians [10].

Our results showed that overall degree of satisfaction with conventional medicine was also a predictor of CAM use. However, this remains controversial. It has been reported that patients tend to use CAM unless they are satisfied with conventional medicine $[10,29]$. Thus, many oncologists worry that patients would discontinue current treatments with the purposes of using CAM alternatively to conventional medicine. On the other hand, there are also contradictory results that dissatisfaction with conventional treatment was not a predictor of CAM use [30], and patients who used CAM expressed as high a degree of trust in conventional medicine and showed as high a degree of compliance as patients who were not interested in CAM [9]. Further studies are needed to clarify the relationship between satisfaction with conventional medicine and CAM use conclusively.

Interestingly, patients who had a greater need for information were more likely to use CAM. According to the questionnaire survey, based on the responses to the nine questions about the degree of patient need for information, other than the question about hospice, a higher degree of informational need was associated with a higher rate of CAM use. These results can be interpreted from two perspectives. (1) A coping style might be involved. That is, patients tend to consider the use of CAM as a way of independently contributing to their treatment if they have an active coping style against the disease and consider their prognosis somewhat hopeful (and their need for information about hospice is accordingly lower). Söllner et al. reported that a coping style characterized by information seeking and active problem solving was a powerful independent predictor of CAM use [9]. (2) The correlation between CAM use and the degree of informational needs may be considered from the perspective of unmet needs. The concept of unmet needs in cancer patients comprises several aspects including information, psychological problems, physical symptoms, and emotional needs [31]. If patients with cancer have unmet needs that include informational aspects, this would tend to decrease the degree of satisfaction with conventional treatment and/or the trust in physicians or hospitals, which might in turn increase the rate of CAM use. It has been reported that patient satisfaction with medical treatments is increased when patients are appropriately provided with information [32]. Following the analysis of data obtained in the current study, a higher degree of informational need was correlated with lower overall satisfaction with conventional medical services and trust in hospitals and a lower degree of trust in physicians or hospitals (data not shown). Due to limitations of this cross-sectional study, however, it was difficult to identify any causal relationship between the variables.

In our clinical series, the overall rate of CAM use following the diagnosis of cancer was $25.5 \%$. This is notably lower than previously reported: $44.6 \%$ in Japan [7], $61.5 \%$ in Australia [12], 51.2\% in Israel [10], and $78-90 \%$ in the United States [3, 5, 6, 33]. Moreover, it is quite different from the $55-65 \%$ in previous Korean reports [19-21]. One possible explanation for this low rate is a slight difference in the definition of CAM between this and the previous studies. Although many studies $[3,5,6,12,19-21]$ defined CAM based on the NCCAM, some [7, 33] used operational definitions of their own, and one study was based on a Cochrane collaboration [10]. Moreover, even if based on NCCAM, the specific modalities of each CAM category listed in the questionnaires varied among the studies. For example, our study excluded general physical exercises, while yoga and qi gong were included in the exercises as CAM. However, many studies did not distinguish between movement therapies and general physical exercises [3, 6, 12, 19-21]. Similarly, the exclusion of support groups and psychotherapy from our definition of CAM may have influenced the result. Another possible explanation for the rate differences is the questionnaire survey method. In studies that reported a high rate of CAM use, the questionnaire was self-administered by patients and returned by mail directly to the researchers $[3,5-7]$. In our study, however, face-to-face interviews were performed by trained interviewers while patients were awaiting treatment. Since some patients felt uncomfortable about disclosing their use of CAM to their physicians, patients who completed a questionnaire survey right before (or after) seeing a doctor in the hospital might have a higher possibility of nondisclosure than those who completed it in their own homes. Consequently, our survey presumably underestimates the actual level of CAM use.

The limitations of the study are as follows. First, the current study is a cross-sectional one. Thus, there are difficulties in identifying any causal relationships between variables. Based solely on our results, it remains unclear whether the degree of patient satisfaction with conventional treatment was decreased because they used CAM or whether patients with a lower degree of satisfaction with conventional treatment tend to use CAM. Second, as mentioned earlier, we cannot completely rule out the possibility that our results might be an underestimate, although there were differences in the definition of CAM between this and the previous studies. This underestimate may affect the whole study. Continued research on the prevalence and predictors of CAM are needed in Korea. Despite these limitations, our results are of significance in that we extensively examined the status of CAM use and relevant factors in patients using a large sample size and various cancers in varying stages.

In conclusion, the use of CAM in patients with cancer can be interpreted as an attempt to explore all possible options, an expression of an active coping style, or an expression of unmet needs in the cancer care continuum. In any case, physicians should openly address the use of CAM and should identify whether there are other unmet 
supportive needs with their patients. Additionally, there should be sufficient communication between physicians and patients, which is essential for forming a trusting physicianpatient relationship.

\section{Conflict of Interests}

The authors declare no conflict of interests.

\section{Acknowledgments}

This study has been supported by a grant from the National Cancer Center (Grant no. 1210150), Republic of Korea. The authors thank all patients who participated in this survey. The authors would also like to thank the reviewers of this paper for their valid suggestions, which contributed to the improvement of the paper.

\section{References}

[1] National Center for Complementary and Alternative Medicine (NCCAM), "What is complementary and alternative medicine?” July 2011, http://nccam.nih.gov/health/whatiscam/.

[2] World Health Organization (WHO), "Fact sheet No. 297," February 2012, http://www.who.int/mediacentre/factsheets/ fs297/en/index.html.

[3] A. M. Gross, Q. Liu, and S. Bauer-Wu, "Prevalence and predictors of complementary therapy use in advanced-stage breast cancer patients," Journal of Oncology Practice, vol. 3, no. 6, pp. 292-295, 2007.

[4] H. S. Boon, F. Olatunde, and S. M. Zick, "Trends in complementary/alternative medicine use by breast cancer survivors: comparing survey data from 1998 and 2005," BMC Women's Health, vol. 7, article 4, 2007.

[5] S. M. Rausch, F. Winegardner, K. M. Kruk et al., "Complementary and alternative medicine: use and disclosure in radiation oncology community practice," Supportive Care in Cancer, vol. 19, no. 4, pp. 521-529, 2011.

[6] J. S. Yates, K. M. Mustian, G. R. Morrow et al., "Prevalence of complementary and alternative medicine use in cancer patients during treatment," Supportive Care in Cancer, vol. 13, no. 10 , pp. 806-811, 2005.

[7] I. Hyodo, N. Amano, K. Eguchi et al., "Nationwide survey on complementary and alternative medicine in cancer patients in Japan," Journal of Clinical Oncology, vol. 23, no. 12, pp. 26452654, 2005.

[8] M. L. Slevin, "Quality of life: philosophical question or clinical reality?” British Medical Journal, vol. 305, no. 6851, pp. 466469, 1992.

[9] W. Söllner, S. Maislinger, A. DeVries, E. Steixner, G. Rumpold, and P. Lukas, "Use of complementary and alternative medicine by cancer patients is not associated with perceived distress or poor compliance with standard treatment but with active coping behavior: a survey," Cancer, vol. 89, no. 4, pp. 873-880, 2000.

[10] O. Paltiel, M. Avitzour, T. Peretz et al., "Determinants of the use of complementary therapies by patients with cancer," Journal of Clinical Oncology, vol. 19, no. 9, pp. 2439-2448, 2001.
[11] A. T. Malak, O. Karayurt, E. Demir, and A. S. Yümer, "Complementary and alternative medicine in cancer patientsanalysis of influencing factors in Turkey," Asian Pacific Journal of Cancer Prevention, vol. 10, no. 6, pp. 1083-1087, 2009.

[12] N. Klafke, J. A. Eliott, G. A. Wittert, and I. N. Olver, "Prevalence and predictors of complementary and alternative medicine (CAM) use by men in Australian cancer outpatient services," Annals of Oncology, vol. 23, no. 6, pp. 1571-1578, 2012.

[13] I. J. Lerner and B. J. Kennedy, "The prevalence of questionable methods of cancer treatment in the United States," CA A Cancer Journal for Clinicians, vol. 42, no. 3, pp. 181-191, 1992.

[14] W. Söllner, M. Zingg-Schir, G. Rumpold, and P. Fritsch, "Attitude toward alternative therapy, compliance with standard treatment, and need for emotional support in patients with melanoma," Archives of Dermatology, vol. 133, no. 3, pp. 316321, 1997.

[15] B. R. Cassileth, E. J. Lusk, T. B. Strouse, and B. J. Bodenheimer, "Contemporary unorthodox treatments in cancer medicine. A study of patients, treatments, and practitioners," Annals of Internal Medicine, vol. 101, no. 1, pp. 105-112, 1984.

[16] J. Kerr, J. Engel, A. Schlesinger-Raab, H. Sauer, and D. Hölzel, "Communication, quality of life and age: results of a 5year prospective study in breast cancer patients," Annals of Oncology, vol. 14, no. 3, pp. 421-427, 2003.

[17] T. F. Hack, L. F. Degner, and D. G. Dyck, "Relationship between preferences for decisional control and illness information among women with breast cancer: a quantitative and qualitative analysis," Social Science and Medicine, vol. 39, no. 2, pp. 279-289, 1994.

[18] M. Tsuchiya and S. A. Horn, "An exploration of unmet information needs among breast cancer patients in Japan: a qualitative study," European Journal of Cancer Care, vol. 18, no. 2, pp. 149-155, 2009.

[19] M. H. Kim, Use of Complementary and Alternative Medicine by Cancer Patient in Korea, Graduate School of Environmental Studies, Yeungnam University, Daegu, Republic of Korea, 2003.

[20] E. I. Lee, Y. C. Shin, J. H. Lee et al., "Use of complementary and alternative medicine in cancer patients at seven general hospitals in Seoul," Journal of Korean Public Health Association, vol. 28, no. 3, pp. 225-238, 2002.

[21] H. S. Park and Y. M. Lee, "A study on the use of alternative therapy in cancer," The Korean Journal of Rehabilitation Nursing, vol. 3, no. 2, pp. 212-227, 2000.

[22] K. H. Choi, J. H. Park, and S. M. Park, "Cancer patients' informational needs on health promotion and related factors: a multi-institutional, cross-sectional study in Korea," Supportive Care in Cancer, vol. 19, no. 10, pp. 1495-1504, 2011.

[23] M. H. Kim, Y. S. Cho, W. S. Uhm, S. Kim, and S. C. Bae, "Cross-cultural adaptation and validation of the Korean version of the EQ-5D in patients with rheumatic diseases," Quality of Life Research, vol. 14, no. 5, pp. 1401-1406, 2005.

[24] E. J. Shim, K. S. Lee, and J. H. Park, "Comprehensive needs assessment tool in cancer (CNAT): the development and validation," Supportive Care in Cancer, vol. 19, no. 12, pp. 1957-1968, 2011.

[25] C. Guethlin, H. Walach, J. Naumann, H. H. Bartsch, and M. Rostock, "Characteristics of cancer patients using homeopathy compared with those in conventional care: a cross-sectional study," Annals of Oncology, vol. 21, no. 5, pp. 1094-1099, 2009.

[26] A. Wanchai, J. M. Armer, and B. R. Stewart, "Complementary and alternative medicine use among women with breast 
cancer: a systematic review," Clinical Journal of Oncology Nursing, vol. 14, no. 4, pp. E45-E55, 2010.

[27] K. T. Morris, N. Johnson, L. Homer, and D. Walts, "A comparison of complementary therapy use between breast cancer patients and patients with other primary tumor sites," American Journal of Surgery, vol. 179, no. 5, pp. 407-411, 2000.

[28] L. M. DiGianni, J. E. Garber, and E. P. Winer, "Complementary and alternative medicine use among women with breast cancer," Journal of Clinical Oncology, vol. 20, no. 18, supplement, pp. 34S-38S, 2002.

[29] M. A. Evans, A. R. G. Shaw, D. J. Sharp et al., "Men with cancer: is their use of complementary and alternative medicine a response to needs unmet by conventional care?" European Journal of Cancer Care, vol. 16, no. 6, pp. 517-525, 2007.

[30] J. A. Astin, "Why patients use alternative medicine: results of a national study," Journal of the American Medical Association, vol. 279, no. 19, pp. 1548-1553, 1998.

[31] D. W. Shin, J.-H. Park, E.-J. Shim, M.-I. Hahm, J.-H. Park, and E.-C. Park, "Predictors and outcomes of feeling of insufficient consultation time in cancer care in Korea: results of a nationwide multicenter survey," Supportive Care in Cancer, vol. 20, no. 9, pp. 1965-1973, 2012.

[32] R. Davidson and M. E. Mills, "Cancer patients' satisfaction with communication, information and quality of care in a UK region," European Journal of Cancer Care, vol. 14, no. 1, pp. 83-90, 2005.

[33] M. A. Richardson, T. Sanders, J. L. Palmer, A. Greisinger, and S. E. Singletary, "Complementary/alternative medicine use in a comprehensive cancer center and the implications for oncology," Journal of Clinical Oncology, vol. 18, no. 13, pp. 2505-2514, 2000. 


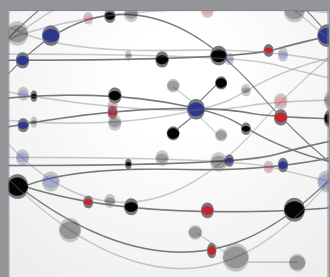

The Scientific World Journal
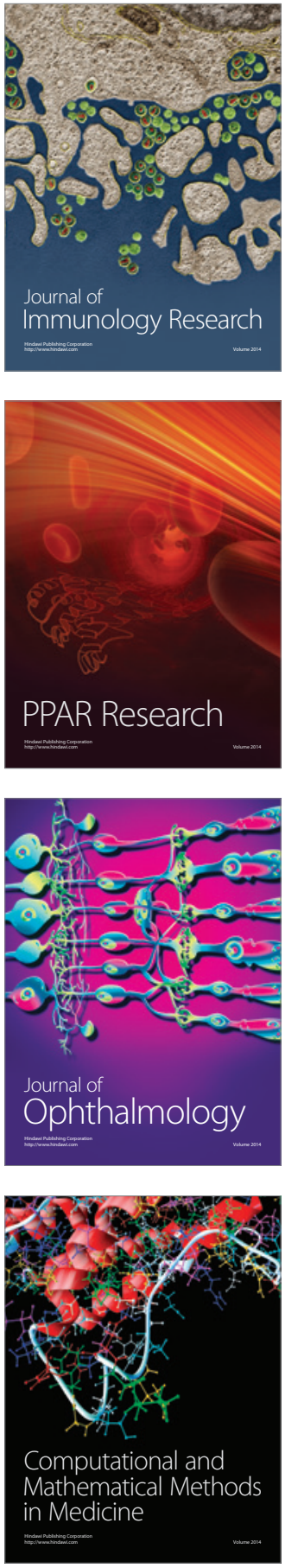

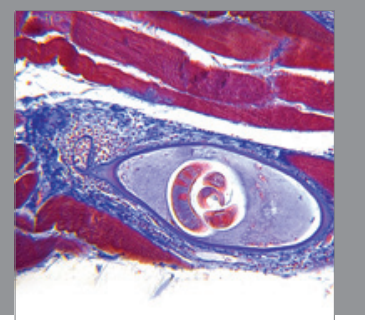

Gastroenterology

Research and Practice
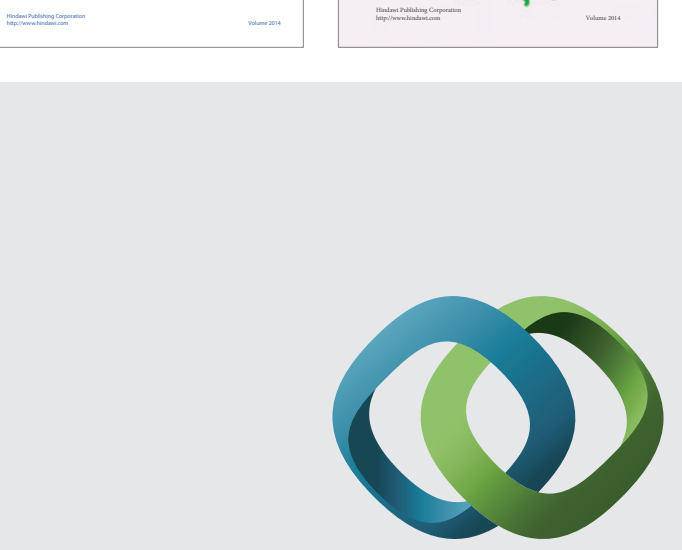

\section{Hindawi}

Submit your manuscripts at

http://www.hindawi.com
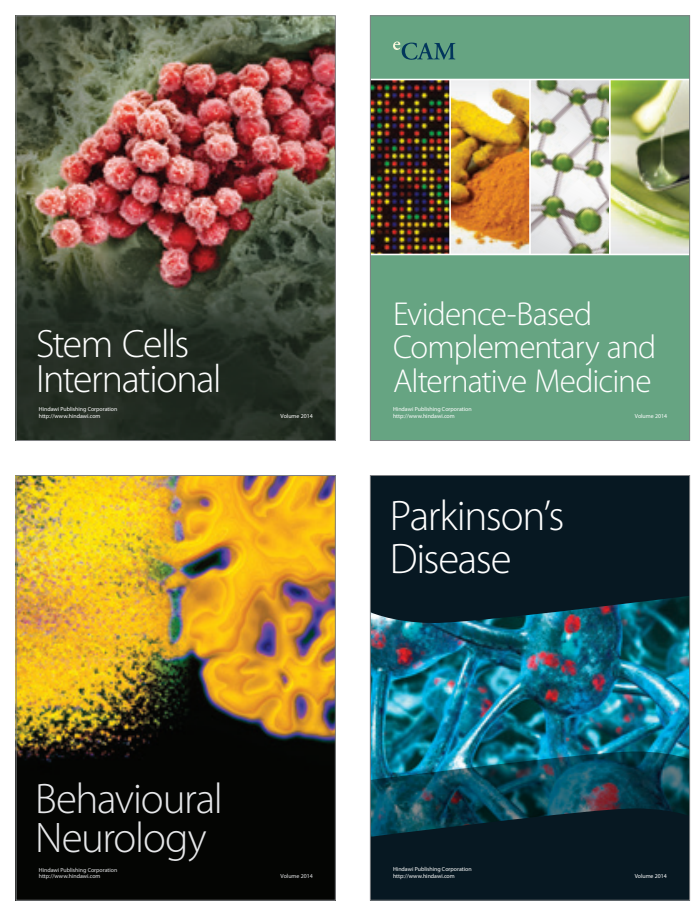

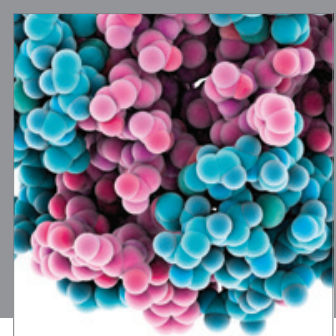

Journal of
Diabetes Research

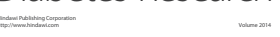

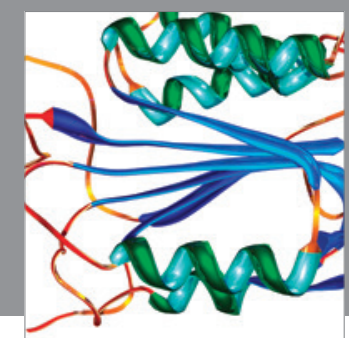

Disease Markers
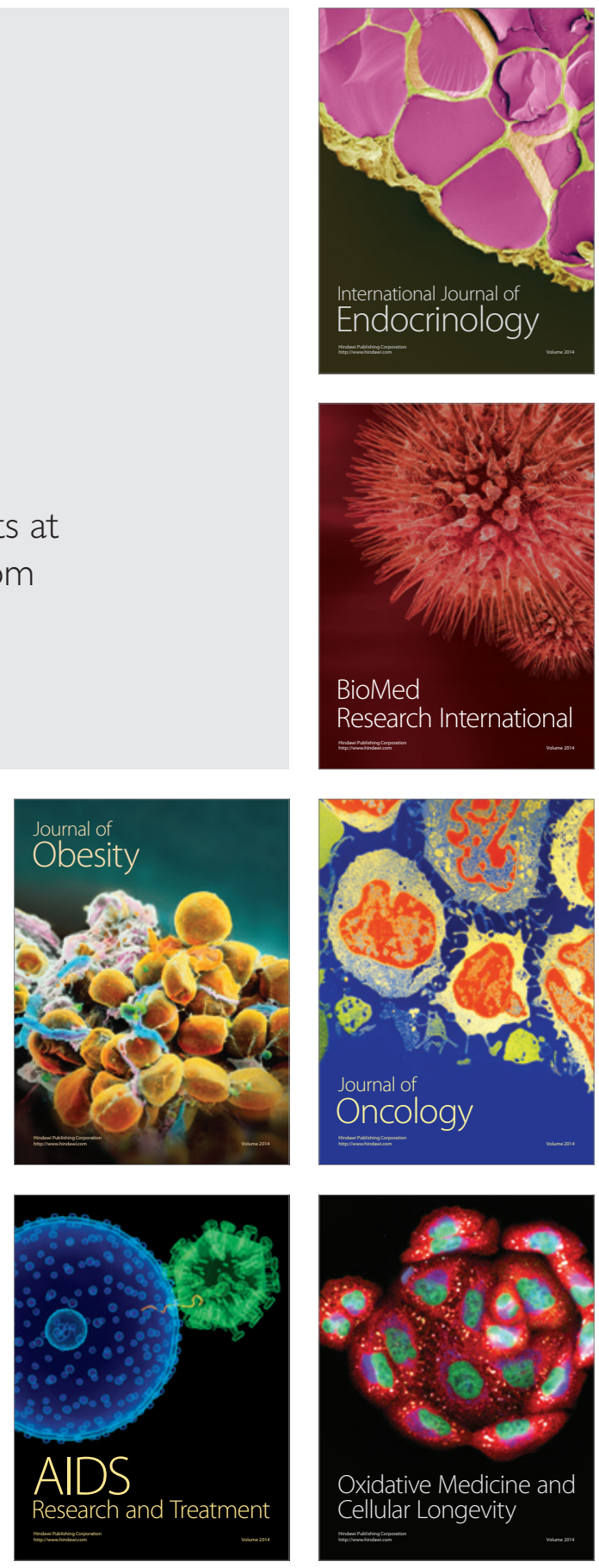